\title{
Influence of Culture on Reactions to Negotiation Deadline
}

\author{
Zhaleh Semnani-Azad \\ Clarkson University \\ zsemnani@clarkson.edu
}

\author{
Wendi Adair \\ University of Waterloo \\ wladair@uwaterloo.ca
}

\author{
Katia Sycara \\ Carnegie Mellon \\ University \\ katia@cs.cmu.edu
}

\author{
Michael Lewis \\ University of Pittsburgh \\ ml@sis.pitt.edu
}

\begin{abstract}
Prior research shows that Western and Eastern individuals behave differently in negotiations due to cultural differences in values, norms, and strategies. In this study we examined cultural differences in how deadlines affect reaching an agreement in negotiations. We also examine various factors that determine negotiators' strategies, such as the number of issues negotiators focus on or the importance placed on relationship building or tasks. Using cultural theories involving time perception we generated hypotheses and tested in an in-lab negotiation experiment with varying time deadline. Our sample included East Asian and North American negotiators engaging in an intracultural negotiation. Our results showed significant main effects. East Asian negotiators were more focused on relationship building and longterm plans than North American negotiators, who were focused on the tasks and short-term plans. We discuss interactions of culture and deadline on negotiation process and performance.
\end{abstract}

\section{Introduction}

As international trade and business grows and becomes more interdependent at the global level, it becomes more and more important to study crosscultural negotiation and which factors lead to a successful outcome [4]. Negotiation is crucial to study, as it is a form of social interaction present in our everyday lives. Negotiation is the process by which two or more parties try to resolve perceived incompatible goals [6]. A lack of understanding of values, ways of communication, and perception and use of time amongst members of other cultures could result in a misunderstanding of cultures during a negotiation. This could result in an unnecessarily lengthy and frustrating interaction and possibly suboptimal outcomes [1,4]. Using Hall's metaphor of negotiation being a dance (1983), it is expected that negotiators from different cultures, just like dancers from different cultures, will behave differently while negotiating, leading to difficulty in synchronization and understanding each other $[14,25,26]$. In the current study, we are interested in examining how negotiators of East Asian and North American cultures react to negotiation deadlines and how this affects the negotiation process.

According to past research, time pressure is not always disadvantageous in negotiations [22]. Final deadlines are fixed time limits that end a negotiation [22]. Final deadlines in negotiation are always symmetric even if parties have different deadlines because if one party leaves, the other party cannot keep negotiating alone. Therefore, the shorter deadline is the only relevant and important deadline [22]. Lim and Murnighan (1994) found that the size and rate of concessions increased as negotiators approached a final deadline [18]. Their study included a bargaining task that represented a basic strategic interaction of two people with differing preferences for different outcomes that must come to a mutual agreement to gain profit. The participants were undergraduate economics students. Each participant bargained in 4 consecutive negotiations, each with a different opponent. Each pair of participants was to negotiate the distribution of 100 tickets in a lottery. The number of concessions made increased as negotiators approached the deadline. The strategy to make a big concession at the very end was appropriate for this task as it helped finalize an agreement and avoid an impasse.

In Moore's (2004) experiments, negotiators viewed short final deadlines as a strategic liability, but the inaccuracy of those beliefs were revealed [22]. In the negotiation, participants were either the buyer or seller and negotiated the price of a widget. The participants were primarily MBA students and undergraduate students. Each buyer was always given a 10 minute deadline, but each seller was given a final deadline of 10 minutes, 3 minutes, or 30 seconds. The negotiators with the most time to negotiate had the worst outcomes. Results showed that the negotiators with a 3 minute final deadline obtained significantly higher prices than did negotiators with a 10 minute final 
deadline. Negotiators with a 30 second final deadline obtained the lowest sale prices amongst all the deadline conditions. They obtained significantly lower prices than did negotiators in the 3 minute final deadline. After the negotiations, participants were then asked to predict the negotiated sale prices in each of the three final deadline conditions. The participants predicted that they would obtain better prices when they had more time to negotiate. This reasoning is due to negotiators predicting egocentrically that their final deadlines will only apply to themselves and hurt only their outcomes and not the other party's [22].

Although outcomes were clearly influenced by the differences in final deadlines, it is possible that they did so by changing the negotiators' aspirations [22]. If this were true, then it would suggest that negotiators were either good at anticipating outcomes and adjusted their aspirations accordingly, or that negotiators' expectations created self-fulfilling behaviour. Both the aspirations of buyers and sellers were significant predictors of outcomes, and the treatment condition effects remained significant, which indicates that the effects of the treatment conditions on negotiated outcomes were not perfectly mediated by changes in the negotiators' expectations. Results showed that the sellers' aspirations were strongly influenced by the treatment conditions (10 minutes, 3 minutes, or 30 seconds), but the treatment conditions had no significant effects on buyers' aspirations (all 10 minutes). This is likely if the buyers were thinking egocentrically, only paying attention to their own time constraints and ignoring those of their opponents since they all had a 10 minute deadline [22].

However, shorter final deadlines are not always beneficial to negotiators. Final deadlines can be too short, like the 30 second deadline, and lead to more impasses because there is just not enough time for negotiators to reach agreement [22]. Lewicki and Litterer (1985) have reviewed the effects of deadlines on behaviour during negotiation and concluded that as deadlines shorten, negotiators soften demands, are less likely to bluff, make more concessions, and become less prone to interpret concessions as a sign of weakness $[3,16]$. Thus, based on prior research we predict that when provided with a shorter deadline, negotiators are more likely to reach an agreement.

Hypothesis 1: Negotiators in the short deadline are more likely to reach agreement.

Prior research shows that deadlines in negotiation could be beneficial and advantageous when used strategically. However, deadlines may not have the same effect in cross-cultural negotiations. Provided that the meaning of time is partially culturally determined, and that culture influences individuals' perception of time and their subsequent behaviour, people in different cultures may hold different values and views on deadlines and time pressure [7, 9, 20]. One's concept of time is always culture-based [7]. For example, in a negotiation, a person of one culture may hold value and importance in deadlines and increase the pressure to finish on time, whereas the other person of another culture may be relaxed because deadlines do not hold much importance in his/her view [12]. The opposing values and perspectives need to be taken into account in cross-cultural negotiations in order to have an efficient negotiation with optimal results.

\section{Time Perception in North American \& East Asian cultures}

Culture is a socially shared meaning system $[8,24$, 25 ] that consists of a group's subjective characteristics (values and norms) and objective characteristics (artifacts and institutions) [5, 20, 25, 26, 27]. Many sources agree that there is a major cultural difference between the East and the West [4]. The West values individualism, egalitarianism, and low-context communication, and the East values collectivism, hierarchy, and high-context communication [4]. However, these distinctions oversimplify the complex cultural differences in negotiation norms, and there are distinct normative differences within regions [4, 15]. To understand people's temporally based behaviours, you have to first examine how people perceive and think about time, or their "temporal perception." North American and East Asian negotiators' temporal perception may be different due to their differing cultural values and norms.

A key dimension of temporal perception in cultures is whether time is symbolized as monochronic or polychronic [7, 11, 12]. Monochronic time (M-time) emphasizes doing things "one thing at a time;" thus, monochronic individuals typically only attempt to do one task at a time [7]. M-time suggests that in order to be efficient in work organizations, you must sort through many solutions and work on tasks one-at-atime to find the single best method [2]. Polychronic individuals do several tasks at one time and are more strongly oriented toward the present and feel less bound to a timetable or a procedure than monochronic individuals. P-time suggests that a number of solutions may resolve the same problem and that they can be examined simultaneously [2].

Members of individualistic cultures tend to follow the M-time pattern, and members of collectivistic cultures tend to follow the P-time pattern [23]. 
Monochronic time represents the traditional Western, Anglo cultural perception of time [7]. North American negotiators will therefore work on tasks one-at-a-time to find the single best solution. Polychronic time is more dominant in East Asian cultures [13, 14, 23]. However, East Asian cultures' view of time is not strictly polychronic. The precision of appointments and schedules is respected (monochronic time characteristics), but once a meeting begins, polychronic time is observed [19]. Hall and Hall (1987) indicated that the Japanese are monochronic in their time use when dealing with "foreigners" and technology, yet act polychronically in all other situations [14, 15, 19]. Therefore, East Asian negotiators are more likely to focus on several issues at once due to their polychronic view of time, although they may have a monochronic view of time in some contexts.

Hypothesis 2: North American negotiators will reach agreement on fewer issues compared to East Asian negotiators.

Polychronic individuals view time as an inexhaustible resource, and interpersonal relations are equally as important, or more, as the work to be done [2, 12]. Individuals of East Asian cultures, being polychronic, view time as standing in the background to immediate personal relationships. They consistently emphasize interpersonal relationships, and the clock is not the ultimate reason for action [17]. Also, in a laboratory simulation, Graham and Mintu-Wimsat (1997) showed that, in East Asian countries, interpersonal relationships have important positive effects on negotiators' satisfaction [17]. For monochronic individuals (for example, North Americans) this is not the case. Their extreme concentration and dedication to their task places it above anything else, including interpersonal communication, either temporarily or more permanently $[2,12]$.

Hypothesis 3: North American negotiators will be more task-focused, while East Asian negotiators will more likely be relationship-focused (H3a).

Satisfaction with the negotiation outcome will depend on negotiators achieving desired goals of relationship building or completing the task (H3b).

We predict that East Asian negotiators will be more satisfied than North American negotiators when given a long deadline since they have more time to build a relationship; East Asian negotiators will be less satisfied than North American negotiators when given a short deadline.

There are two perspectives of time known as linear time and cyclical time [21]. People who view time monochronically, like North American individuals, see time as linear and separable, capable of being divided into units [7]. Viewing time as linear means that irreversible flow replaces recurrence [21]. The personal experience of one's life from birth to death is an irreversible process, and important moments are marked by events, rather than the minutes or hours of the clock [21]. Individuals' view of time as an irreversible flow may possibly place greater emphasis on deadlines and time pressure than individuals who view time as cyclical. People who view time polychronically, like East Asian individuals, see time as naturally re-occurring in cycles [7, 9]. Cyclical time emphasizes the predictable, recurring, and generalizable elements of time [21]. It is related to various forms of repetitive motion, which may be periodic (phasic, epochal, seasonal) or monotonic (subject to replication, recurrence, and prediction). Cyclical time is a view of time inspired by renewal, periodicity, and repetition, like the four seasons or the sunset and sunrise [21]. In all cultures, the notions of cyclical or linear time have a great influence on the way people perceive themselves, and select and pursue personal and social goals [21].

Hypothesis 4: North American negotiators, having a linear view of time, will focus on deadlines more than East Asian negotiators, who have a cyclical view of time.

\section{Methods}

\subsection{Design}

The experiment was a 2 (Culture: North American, East Asian) x2 (Deadline: Short, i.e. 5 minutes, Long, i.e. 20 minutes) factorial design.

The dependent measures in the experiment were 1) whether negotiators were able to reach agreement, 2) the number of issues (multiple vs. only a few) negotiators agreed on (see Appendix A for additional information), 3) the types of issues they focused on during the negotiation (relational vs. task focus) (see Appendix B for additional information), 4) satisfaction with negotiation, 5) time perception, and 6) attention to deadline.

\subsection{Participants}


A total of 98 participants from East Asian ( $\mathrm{N}=32)$ and North American $(\mathrm{N}=66)$ cultural backgrounds took part in a study about decision-making in negotiations. Participants were undergraduate students at a large Canadian university that signed up for a lab experiment to receive either course credit or financial compensation. All East Asian participants lived in Canada for less than 10 years, were born and raised in an East Asian country, and identified with the ethnic East Asian culture. The North American participants were Canadians with European heritage, born and raised in Canada and only affiliated with the Canadian culture. Participants were randomly placed in either the short or long deadline condition.

\subsection{Negotiation Simulation}

The negotiation simulation involved two participants in the role of a seller and buyer. The seller's role was a sales representative of a film production company, Hollyfilm. The buyer was a general manager of WCHI, a television station. The participants were to negotiate on the sale of syndication rights (reruns) for a children's cartoon, Ultra Rangers. The main issues to be negotiated were 1) price per episode, 2) runs per episode, 3) future deals, and 4) future revenue sharing. Each role had different preferences for the price and runs per episode. The issues were calculated on a point system where participants can calculate their net profit of the cartoon and also the net value of the bargaining agreement in comparison to their alternative deal. Both parties were offered an alternative deal from another television station or producer, so reaching agreement with each other was not mandatory. Participants were given either 5 or 20 minutes for negotiation depending on which deadline condition they were placed in.

\subsection{Negotiation Surveys: Pre and Post}

The Pre-negotiation Questionnaire was comprised of four broad components. First it included questions pertaining to Importance of Negotiation Issues. These set of questions asked the participants about 1) which issues they think they will reach agreement on and 2) the ranking of importance of those issues (from 1 to 4).

The second component included the Use of Time Questionnaire, which included items from the Communication and Social Interaction Style (CSIS) framework, and previously validated self-report measure [28, 30]. This measure captured multiple facets of how one uses time during a negotiation context. These factors include: 1) Focus on Relationship, i.e. the extent to which individuals focus on relationship building, 2) Focus on Issues, i.e. the extent to which individuals focus on the negotiation issues and task at hand, 3) Focus on Long-term, i.e. the extent to which negotiators try to develop and build long-term relationship, and 4) Focus on Short-term, i.e. the extent to which negotiators focus on immediate plans and decisions.

The third section included items pertaining to Anticipation of Negotiation Completion. Participants were provided with items measuring the likelihood they would need more time or would engage in future interactions with their negotiating partner.

The fourth section included items pertaining to Anticipated Pleasantness. In these set of items, participants were asked to complete a questionnaire measuring their anticipated pleasantness of the upcoming negotiation interaction.

The Post-Negotiation Questionnaire included items the focused on the actual experience of time during the negotiation. Specifically, the items asked about what participants actually focused on and how satisfied they were with their outcomes and the time given for the negotiation. All self-report measure employed a 7point likert scale with 1 as "strongly disagree" and 7 representing "strongly agree."

\subsection{Time Perception Survey: Cultural Norm}

After the completion of the post-negotiation questionnaire, participants completed a last set of selfreport measure specifically focusing on cultural norms associated with time perception. The online questionnaire completed at the end of the study tapped onto how participants scheduled their time and focused on deadlines. It included The Communication and Social Interaction Style (CSIS) Time Scale [28], which measures how individuals perceive time and deadlines, and how they schedule and use their time. Participants were given the GLOBE Future Orientation scale and the Long-term Orientation [29] to measure the extent to which individuals from different cultures emphasize on the future and planning ahead rather than focusing on the present.

\subsection{Procedure}

The study consisted of three parts: Pre-negotiation, Negotiation, and Post-negotiation. When participants came in, they were placed in separate rooms and were provided with instructions separately. Each participant was given a brief introduction of the study and asked to read and sign the consent form. The participant was then asked to read his/her given role of either seller or buyer of a children's cartoon, Ultra Rangers, and fill out the pre-negotiation questionnaire. Following the 
instructions, the experimenter would leave the room to give instructions to the other participant in the other room. The participants were given around 25 minutes to complete this section of the study.

When both participants completed their role preparation and pre-negotiation questionnaires, the participants were brought together into the main room for the negotiation. The participants were given instructions about the negotiation, and they were given either 5 or 20 minutes to negotiate. The issues were price per episode for the syndication of the cartoon and the number of runs per episode (the number of times each episode may be shown during the fixed five-year contract). The negotiations were stopped at the assigned deadlines, regardless if the participants had reached agreement or not, or ended when the participants reached an agreement before the deadline was over. A result sheet was given to the participants to record what they had agreed upon, their future deals, and their corresponding net profit from the negotiation.

After the negotiation, the participants were separated again, and one of the participants was taken to the other room. Participants were then given two post-negotiation questionnaires to complete, one written and the other one online on a computer. Upon completion of the questionnaires, participants were questioned for suspicion, debriefed, and granted their 1.5 credits or $\$ 15$.

\section{Results}

A series of univariate analysis of variance was conducted to examine the results for Hypothesis 1, 2, and $3 \mathrm{~b}$. Univariate analysis of variance general linear model was used for Hypothesis 2, 3a, and 4. We first hypothesized that negotiators in the short deadline are more likely to reach agreement than those in the long deadline (H1). The results showed a significant difference between the deadline conditions, $F(1,94)=$ 7.83, $\mathrm{p}<0.01$. However, negotiators in the long deadline condition were more likely to reach agreement $(\mathrm{M}=0.94, \mathrm{SE}=0.05)$, and negotiators from the short deadline were more likely to impasse $(\mathrm{M}=$ $0.74, \mathrm{SE}=0.05)$, regardless of the culture. Therefore, the hypothesis is supported in the reverse direction.

In Hypothesis 2, we predicted that North American negotiators will reach agreement on fewer issues compared to East Asian negotiators. To test this hypothesis, we examined cultural differences in the negotiators' responses for the number of issues they thought they could reach agreement on, given their specified deadline. The issues included price per episode for the cartoon, runs per episode, future deals together, and future revenue sharing. We also examined cultural differences in the likelihood that negotiators thought they would reach agreement on all the issues by the deadline and the likelihood that they thought the negotiation would end before the time deadline.

Results showed that there were no significant differences between the results of North American and East Asian negotiators for the number of issues of agreement, $\mathrm{F}(1,93)=0.11, \mathrm{p}>0.05$. However, we observed a pattern in the direction of the hypothesis, such that East Asian negotiators were more likely to indicate that they would reach agreement on more issues than North American negotiators, regardless of the deadline. A marginally significant cultural difference was found for the "likelihood that the negotiators would reach agreement on all issues by the end of the deadline," $F(1,94)=3.78, p=0.055$. Overall, East Asian negotiators assumed they would agree on more issues $(\mathrm{M}=3.91, \mathrm{SE}=0.28)$ than the North American negotiators $(\mathrm{M}=3.24, \mathrm{SE}=0.20)$, regardless of the deadline.

We also tested for "the likelihood that negotiators thought that the negotiation would end before the deadline." There was no main effect of culture, but there was a marginally significant interaction of Culture x Deadline, F $(1,94)=2.87, \mathrm{p}=0.094$ (See Figure 1).

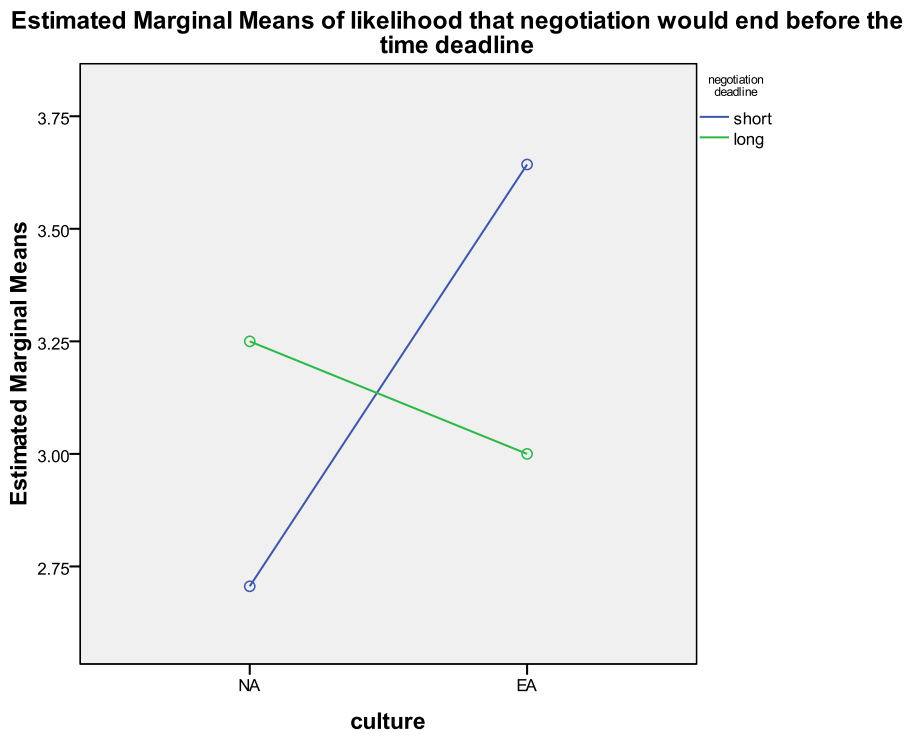

Figure 1. Anticipated Negotiation Completion

In $\mathrm{H} 3 \mathrm{a}$, we hypothesized that North American negotiators will be more task-focused, while East Asian negotiators will be more relationship-focused. To capture relationship focus, we examined measures pertaining to relationship building and long-term focus, such as "I will try to get to know my negotiating partner better" and "At the negotiation, I will mention 
some possible future plans together." To examine task focus, we examined measures related to focus on issues and short-term focus, such as "I would like to focus only on the negotiation issues" and "At the negotiation, I plan on focusing only on short-term, immediate plans." The results illustrate a significant difference in culture for relationship building, "getting to know my negotiating partner better," $\mathrm{F}(1,93)=5.69$, $\mathrm{p}<0.05$. East Asian negotiators $(\mathrm{M}=4.95, \mathrm{SE}=0.25)$ were more likely to want to build a relationship with their partner than were the North American negotiators $(\mathrm{M}=$ 4.22, $\mathrm{SE}=0.17$ ), regardless of the deadline.

There were no significant cultural differences for the negotiators' focus of issues, $F(1,94)=1.38, p>$ 0.05. However, the pattern of results in which North American negotiators ( $\mathrm{M}=4.86, \mathrm{SE}=0.19$ ) would be more task-focused than East Asian negotiators $(\mathrm{M}=$ 4.47, $\mathrm{SE}=0.27$ ) matches our predicted hypothesis. For negotiators' focus on future plans, there was a significant cultural difference, $\mathrm{F}(1,94)=5.22$, p < 0.05. East Asian negotiators $(\mathrm{M}=5.13, \mathrm{SE}=0.21)$ were more likely to "mention some possible future plans together" than were North American negotiators $(\mathrm{M}=4.54, \mathrm{SE}=0.15)$. There was also a marginally significant interaction of Culture x Deadline, F $(1,94)$ $=3.84, \mathrm{p}=0.053$ (See Figure 2). East Asian negotiators were more likely to focus on long-term plans during the long deadline condition $(\mathrm{M}=5.61, \mathrm{SD}$ $=0.98)$ than in the short condition $(\mathrm{M}=4.64, \mathrm{SD}=$ 1.28).

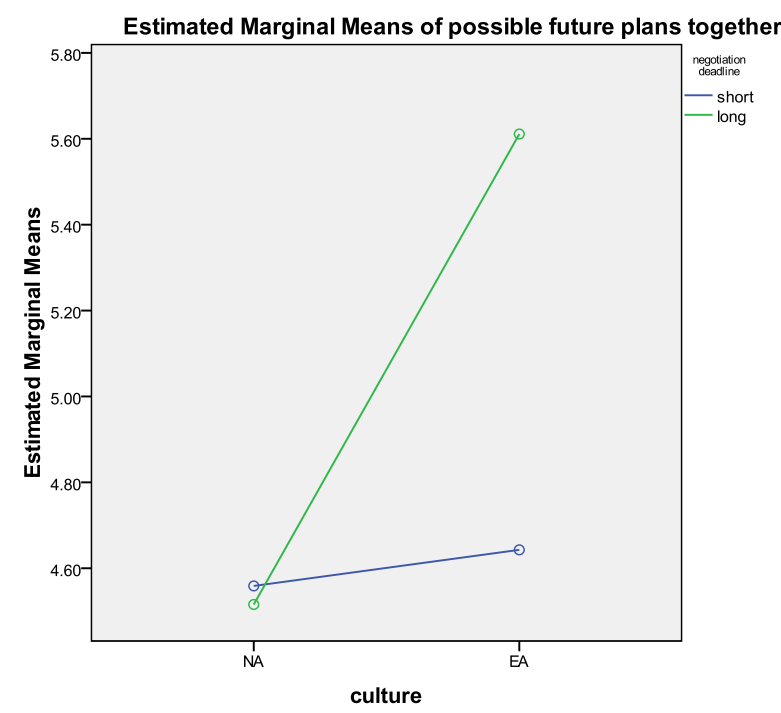

Figure 2. Anticipated Future Relationship

There was a significant cultural difference for the focus on short-term plans, $\mathrm{F}(1,94)=6.15, \mathrm{p}<0.05$. Overall, North American negotiators $(\mathrm{M}=4.52, \mathrm{SE}=$ 0.17) were more likely to focus on short-term, immediate plans than East Asian negotiators $(\mathrm{M}=$ 3.76, $\mathrm{SE}=0.25$ ). Hypothesis $3 \mathrm{~b}$ predicted that East Asian negotiators will be more satisfied than North American negotiators when given a long deadline since they have more time to build a relationship, and will be less satisfied than North American negotiators when given a short deadline. We looked at an average score of responses of anticipated pleasantness for the negotiation to measure the satisfaction with the upcoming negotiation. Measures included anticipating the negotiation task to be "pleasant," "enjoyable," and "satisfying." Results showed a significant cultural difference, $\mathrm{F}(1,93)=8.40, \mathrm{p}<0.01$. Overall, East Asian negotiators $(\mathrm{M}=4.85, \mathrm{SE}=0.19)$ anticipated greater pleasantness than did North American $(\mathrm{M}=$ $4.18, \mathrm{SE}=0.13$ ) negotiators. Hence, Hypothesis 3 was partially supported.

Hypothesis 4 predicted that North American negotiators will focus on deadlines more than East Asian negotiators. To test this hypothesis, we examined the responses of measures for the negotiators' perception of time, such as "Negotiation felt rushed" and "I was frustrated with the amount of time we have." There was a main effect of culture, but it was reverse to our predictions and was marginally significant, $F(1,94)=3.73, p=0.057$. East Asian negotiators $(\mathrm{M}=4.15, \mathrm{SE}=0.32)$ felt that the negotiation was more rushed than did North American negotiators $(\mathrm{M}=3.40, \mathrm{SE}=0.22)$, regardless of the deadline. Therefore, Hypothesis 4 was supported in the reverse direction of our prediction.

\section{Discussion}

The purpose of this study was to examine cultural differences in negotiation with specified deadlines. We were particularly interested in the effects of deadlines in negotiations and the negotiators' strategies, items of focus, and perception of time in negotiations. We observed that when provided with a long deadline, negotiators were more likely to reach agreement. The negotiators were more likely to impasse when provided a short deadline because the deadline may have been too short; there may have just been not enough time to reach an agreement [22]. There was no cultural difference for the number of items negotiators focused on, but we saw a pattern which indicated that East Asian negotiators were more likely to reach agreement on more issues than North American negotiators. A possible reason for not finding any main effects is that the sample size of East Asian participants was too small in comparison to the sample size of North American participants (32 versus 66). 
There was a cultural difference for the likelihood that negotiators thought they would reach agreement on all of the issues by the end of the deadline. East Asian negotiators were more likely to think this way than were North American negotiators, regardless of the deadline. We observed that East Asian negotiators were more likely to focus on relationship building and possible long-term plans than the North American negotiators. East Asian negotiators' focus on possible future plans could be tied to their focus on relationship building, as relationship building is a long-term process. Although there was no cultural difference for negotiators' focus on issues, we observed a pattern that matched our predictions of North American negotiators focusing on issues more than East Asian negotiators.

We observed a cultural difference where North American negotiators focused more on short-term, immediate plans than East Asian negotiators. Like our predictions, East Asian negotiators had higher anticipated pleasantness for the negotiation than did North American negotiators. Reverse to our predictions on negotiators' perception of time, it was the East Asian negotiators that felt more rushed in the deadlines than did the North American negotiators. East Asian negotiators may have focused more on deadlines because they value the precision of appointments and schedules (monochronic characteristics) since they are not strictly polychronic [19]

We observed a marginally significant interaction of Culture x Deadline for the likelihood that negotiators thought the negotiation would end before the deadline. Simple effects showed that the interaction was driven by cultural differences in the short deadline condition. East Asian negotiators thought they would reach agreement on more issues in the short deadline, but not in the long deadline. We also observed a marginally significant interaction of Culture $\mathrm{x}$ Deadline for negotiators' focus on future or long-term plans. East Asian negotiators focused on future plans more in the long deadline, possibly because in the long deadline, they have already had sufficient time to build a relationship with the partner, which encouraged a longterm relationship.

\section{Limitations, Contributions, and Directions for Future Research}

Limitations in this study include the small sample size of East Asian participants. The East Asian sample being less than half of the North American sample (32 versus 66) is a major limitation. If the sample sizes were equal or similar, the patterns that matched our hypothesis for many of the items may have been significant and more prominent. Another limitation is that the study was conducted in a lab setting rather than in a real-life situation. The effects may be more conservative due to the in-lab setting since this was a simulation performed by students and not a real negotiation. Stronger effects may be observed in a reallife setting where the time pressure and deadline will be real and more salient. The negotiators would participate in an important, relevant negotiation and would work harder to achieve optimal outcomes.

This study helps support previous research on cultural differences in negotiators' focus and behaviour in a negotiation. This study contributes to crosscultural research in behaviours, thought process, and strategies during negotiation. The results from this study could be practically used for businesses and organizations that work internationally with members of East Asian or collectivist cultures. By better understanding the foreign partners' values, thought processes, and strategies in negotiation, inter-cultural negotiating will be smoother and more efficient.

Future research could make the deadline more salient to the negotiators by having a timer or a clock to count down the minutes of the deadline. This awareness of the remaining time could make the effects of deadline more prominent for negotiators who focus greatly on deadlines and completing tasks on time. The time for role preparation could also be increased so all participants know exactly what would be beneficial to their company and what would be considered "optimal outcomes." Participants not fully understanding the experiment materials could result in a slower negotiation, which will require more time to complete the negotiation since participants may be still figuring out their roles instead of negotiating straight away.

\section{References}

[1] Adair WL, Okumura T, Brett JM. Negotiation behavior when cultures collide: the United States and Japan. Journal of Applied Psychology. 2001 Jun;86(3):371.

[2] Benabou C. Polychronicity and temporal dimensions of work in learning organizations. Journal of Managerial Psychology. 1999 Jun 1;14(3/4):257-70.

[3] Bluedorn, A.C. \& Denhardt, R. B. Time and Organizations. Journal of Management, 14, 1988, 299-320.

[4] Brett, J. Culture and Negotiation. International Journal of Psychology, 35 (2), 2000, 97-104.

[5] Brett, J. Negotiating Across Cultures. Jossey-Bass, San Francisco, CA. 2001 
[6] Carnevale, P., \& Pruitt, D.G. Negotiation and mediation. Annual Review of Psychology, 43, 1992, 531-582.

[7] Cotte, J. \& Ratneshwar, S. Juggling and hopping: what does it mean to work polychronically? Journal of Managerial Psychology, 14, 1999, 184-204.

[8] Geertz, C. The Interpretation of Cultures. Basic Books, New York. 1973

[9] Graham, R.J. The role of perception of time in consumer research. Journal of Consumer Research, 7, 1981, 335-342.

[10] Graham, J. L. \& Mintu-Wimsat, A. Cultural Influence on Business Negotiations in Four Countries. Group Decision and Negotiation, 6, 483-502., 1997

[11] Hall, E.T. The Silent Language, Doubleday, New York, NY., 1959

[12] Hall, E.T. The Dance of Life, Doubleday, New York, NY. 1983

[13] Hall, E. T. The Silent Language. Anchor, Garden City, NY. 1983

[14] Hall, E. T. \& Hall, M. Hidden differences: Doing business with the Japanese. Garden City, NY: Anchor Press/Doubleday. 1987

[15] Leung, K., \& Tjosvold, D. Conflict management in the Asia Pacific. Singapore: Wiley. 1998

[16] Lewicki, R. J., \& Litterer, J. A. Negotiation. Homewood, IL: Irwin. 1985

[17] Li, J. \& Labig, C. E. Negotiating with China: Exploratory study of relationship-building. Journal of Managerial Issues, 13, 2001, 345-360.

[18] Lim, S. G.-S., \& Murnighan, J. K. Phases, deadlines, and the bargaining process. Organizational Behaviour and Human Decision Processes, 58, 1994, 153-171.

[19] Lindquist, J. D., Knieling, J., \& Kaufman-Scarborough, C. Polychronicity and Consumer Behavior Outcomes Among Japanese and U.S. Students: A Study of Response to Culture in a U.S. University Setting. Proceedings of the Tenth Biennial World Marketing Congress, 2001.

[20] Lytle, A. L., Brett, J. M., Barsness, Z. I., Tinsley, C. H., \& Janssens, M. A paradigm for confirmatory cross-cultural research in organizational behaviour. Res. Organ. Behavior, 17, 1995, 167-214.

[21] Mainemelis, C. Time and Timelessness: Creativity in (and out of) the Temporal Dimension. Creativity Research Journal, 14, 2002, 227-238.
[22] Moore, D. A. The unexpected benefits of final deadlines in negotiation. Journal of Experimental Social Psychology, 40, 2004, 121-127.

[23] Ting-Toomey, S. Communicating Across Cultures. New York, NY: The Guilford Press. 1999

[24] Triandis, H. C. The Analysis of Subjective Culture. Wiley, New York. 1972

[25] Adair, W. L., \& Brett, J. M. The Negotiation Dance: Time, Culture, and Behavioural Sequences in Negotiation. Organizational Science, 16, 2005, 33-51.

[26] Semnani-Azad Z, Adair WL. The Display of 'Dominant' Nonverbal Cues in Negotiation: The Role of Culture and Gender. International Negotiation. 2011, 26;16(3):451-79.

[27] Semnani-Azad, Zhaleh, and Wendi L. Adair. "Watch your tone... relational paralinguistic messages in negotiation: The Case of East and West." International Studies of Management \& Organization 43, no. 4 (2013): 64-89.

[28] Adair, Wendi L., Nancy R. Buchan, X. Chen, and Dong Liu. "A model of communication context and measure of context dependence." Academy of Management Discoveries 2 (2015): 198-217.

[29] Bearden, W. O., R. Money, B., and Nevins, J.L. "A measure of long-term orientation: Development and validation." Journal of the Academy of Marketing Science 34.3 (2006): 456-467.

[30] Buchan, Nancy R., Wendi L. Adair, and Xiao-Ping Chen. "Navigating international negotiations: A communications and social interaction style (CSIS) framework." Negotiation excellence: Successful deal making 277 (2011).

\section{Appendix A: Ranking of Issues}

In the upcoming negotiation you will be negotiating with your partner for (5 or 20) minutes about purchase of cartoon shows. You and your counterpart should try to reach agreement on 4 issues during the time given. Prior to the negotiation we would like you to consider the amount of time you have to negotiate. Based on this time please rank order the issues in order of importance such that the most important issue will be focused on first, and less important issues may be focused on later or not at all.

Also, we would like you to predict which of the issues you'll reach agreement on, given the time deadline. Below, for the "Reached Agreement" column, please check the box next to the issues for which you think you could reach agreement during the negotiation time. 


\begin{tabular}{|c|c|c|}
\hline $\begin{array}{c}\text { Reached } \\
\text { Agreement } \\
\text { (check all that } \\
\text { apply) }\end{array}$ & $\begin{array}{c}\text { Rank Order of issues } \\
\text { (1=most important } \\
\text { issue, 2=second most } \\
\text { important issue, etc.) }\end{array}$ & \\
\hline$\square$ & & Issues \\
\hline$\square$ & & Price per episode of Ultra Rangers \\
\hline$\square$ & & Runs per episode \\
\hline$\square$ & & Future revenue sharing (tie-ins, etc.) \\
\hline
\end{tabular}

\section{Appendix B: Use of Time Questionnaire}

You have (5 or 20) minutes to complete the negotiation. Based on the time provided for the upcoming negotiation, please indicate your agreement with the following statements.

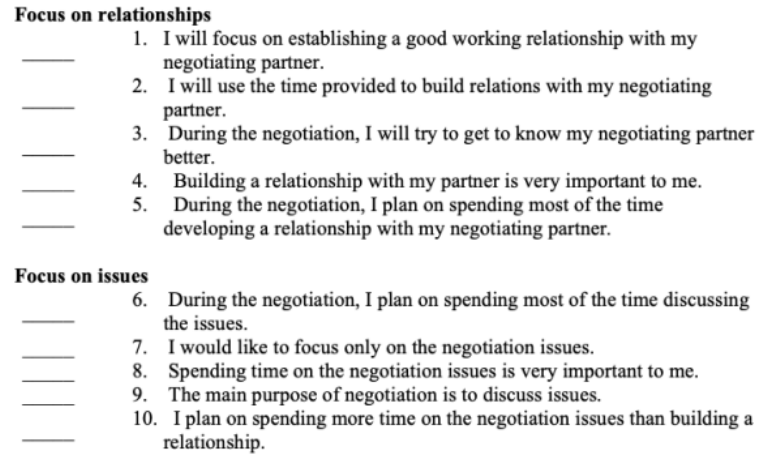

Focus on long-term
11. At the negotiation, I will mention some possible future plans together.

12. I plan on discussing the negotiation in terms of long-term, future plans.

13. At our negotiation, I would like my partner and me to make plans for

the future.

14. This negotiation requires interactions in the future.

15. Discussing the future is very important to me.

Focus on short-term

16. At the negotiation, I plan on focusing only on short-term, immediate

plans.

17. Negotiations only require short-term decision making.

18. I am only interested in discussing the immediate plans.

19. I am not interested in focusing on long-term, future plans.

20. I would like to concentrate of our current plans only. 